\title{
FIELD INVESTIGATIONS ON THE LATERAL VIBRATION FEATURES OF PRESTRESSED CONCRETE STRESS RIBBON FOOTBRIDGES
}

\author{
Saiji Fukada ${ }^{1, a}$, Chen $\mathrm{Xu}^{2}$, Taku Yoshikawa ${ }^{3}$ and Meguru Tsunomoto ${ }^{4}$ \\ ${ }^{1}$ Associate Professor, Kanazawa University, Kakuma-Machi Kanazawa, Japan \\ ${ }^{2}$ Research Associate, Kanazawa University, Kakuma-Machi Kanazawa, Japan \\ ${ }^{3}$ Master Engineering, Oriental Shiraishi Corporation, 5-6-52 Toyosu Koto-Ku Tokyo, Japan \\ ${ }^{4}$ Doctor Engineering, Oriental Shiraishi Corporation, 5-6-52 Toyosu Koto-Ku Tokyo, Japan
}

\begin{abstract}
The prestressed concrete (PC) stress ribbon footbridge is a type of suspension bridge without towers, which has been applied in Japan and all over the world for years in light of its low construction cost and aesthetic merit. It generally consists of the precast concrete slabs with embedded cables. However, the walking-induced lateral vibration trouble of the Millennium Bridge in London in 2000 gave a lesson to the engineers that the lateral vibration feature must be taken into consideration for the footbridge vibration evaluation. In this sense, the field investigations on the lateral vibration features of 14 pre-stressed concrete stress ribbon footbridge in Japan was carried out by artificial impact and damping free vibration tests. According to the investigations, the larger the bridge span, the lower the frequencies of lateral-related vibration modes. In addition, based on the damping-free vibration field tests, there was a tendency toward the damping constant degradation when bridge span became larger.
\end{abstract}

\section{Introduction}

A prestressed concrete (PC) stress ribbon footbridge, which is a type of suspension bridge without towers, consists of precast concrete slabs embedded with cables [1]. Because of its lightweight structure, this type of bridge is more susceptible than normal girder bridge to vibration caused by walking pedestrians. Therefore, the vibration serviceability for this type of bridge needs to be verified.

Research on large lateral vibrations induced by the synchronous walking of pedestrians in the cable-stayed bridge (T-bridge) was first investigated in 1993, and the mechanism of lateral vibrations was clarified [2]. Moreover, the same large lateral vibrations in the stress ribbon pedestrian bridge (London Millennium Bridge) were reported in 2000 [3]. Furthermore, field measurements of lateral vibrations on a pedestrian suspension bridge (M-bridge) were performed [4].

In this study, the vibration tests were performed for 14 single span prestressed concrete stress ribbon footbridge with various span lengths under human-induced excitation to assess the vibration characteristics (natural frequency, modal shape, and damping constant) of the bridges. On the basis of the experimental results, the performances of the lateral vibration serviceability for these bridges were estimated by using Hivoss guidelines [5] that are one of the footbridge design guidelines to propose the vibration serviceability performance of the footbridge due to the walking of pedestrians.

\footnotetext{
${ }^{a}$ Corresponding author: xuchenprc@hotmail.com
}

\section{Stress ribbon footbridges}

To investigate the vibration characteristics (natural frequency, modal shape, damping constant), the examinations under human-induced excitation were conducted for 14 single span stress ribbon footbridges. Table 1 lists the span length, total width, effective width, thickness of deck, and span/sag ratio for each of these bridges. The ranges of the span and span/sag ratio for the bridges studied here are 45.0 to $147.6 \mathrm{~m}$ and 30.0 to 42.2 , respectively.

Table 1. Object stress ribbon footbridges.

\begin{tabular}{|r|r|r|r|r|l|}
\hline $\begin{array}{c}\text { Span } \\
\text { length } \\
(\mathrm{m})\end{array}$ & $\begin{array}{c}\text { Total } \\
\text { width } \\
(\mathrm{m})\end{array}$ & $\begin{array}{c}\text { Effective } \\
\text { width } \\
(\mathrm{m})\end{array}$ & $\begin{array}{c}\text { Thickness } \\
\text { of deck } \\
(\mathrm{m})\end{array}$ & $\begin{array}{c}\text { Span/sag } \\
\text { ratio } \\
(-)\end{array}$ & Remarks \\
\hline 147.6 & 3.64 & 2.5 & 0.250 & 42.2 & \\
\hline 123.0 & 3.3 & 1.5 & 0.200 & 30.0 & \\
\hline 115.0 & $2.00-5.00$ & $1.50-4.50$ & 0.170 & 32.9 & widening \\
\hline 105.0 & 2.0 & 1.3 & 0.200 & 32.9 & \\
\hline 97.0 & $2.10-4.00$ & $1.50-3.40$ & 0.200 & 38.8 & widening \\
\hline 94.0 & 2.3 & 1.5 & 0.200 & 34.8 & \\
\hline 91.0 & 3.3 & 2.5 & 0.220 & 41.4 & \\
\hline 79.0 & 3.3 & 2.5 & 0.200 & 31.6 & \\
\hline 78.0 & 2.0 & 1.5 & 0.190 & 34.7 & \\
\hline 76.5 & $2.00-3.50$ & $1.50-3.00$ & 0.180 & 34.8 & widening \\
\hline 63.0 & 3.0 & 2.5 & 0.200 & 37.1 & \\
\hline 60.0 & 2.8 & 2.0 & 0.200 & 33.3 & \\
\hline 51.0 & 2.5 & 2.0 & 0.200 & 36.4 & \\
\hline 45.0 & 2.5 & 2.0 & 0.170 & 40.7 & \\
\hline
\end{tabular}




\section{Observations of actual bridges}

\subsection{Measurement points}

The measurement points on the bridge with span length $\mathrm{L}$ are shown in Fig. 1. The velocity of the bridge was measured every $1 / 8$ of the span in the vertical direction, and at $1 / 4,1 / 2$, and $3 / 4$ of the span in the horizontal direction. The measured velocity data were recorded in a digital data recorder through the velocity amplifier.

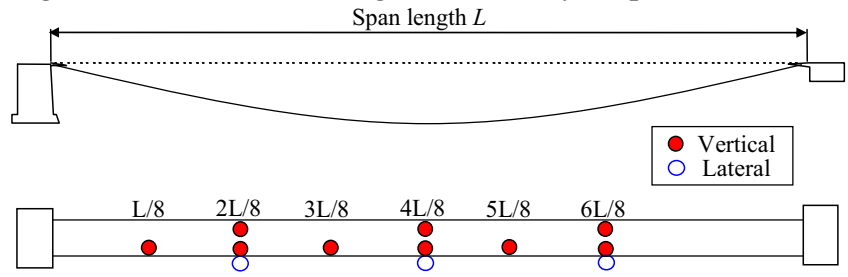

Figure 1. Measurement points on the bridge.

\subsection{Impact test for human weight}

Impact tests were performed to investigate the dominant frequencies of the bridges. The impact tests for the bending (or torsional) vibration mode were conducted by having two people jump from a chair at the same time, as shown in Photo 1. Moreover, impact tests for the torsional-lateral vibration mode were also conducted by having two people jump onto the wheel guard at the same time, as shown in Photo 2. After the impact force due to jumping at the anti-node position of each vibration mode had subsided, the damping-free vibration was recorded. The loading points were at $1 / 4,1 / 2$, and $3 / 4$ of the span.

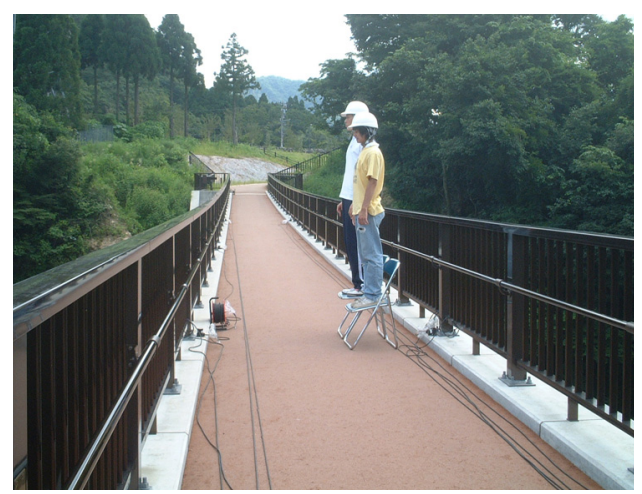

Photo 1. Impact test for vertical vibration mode.

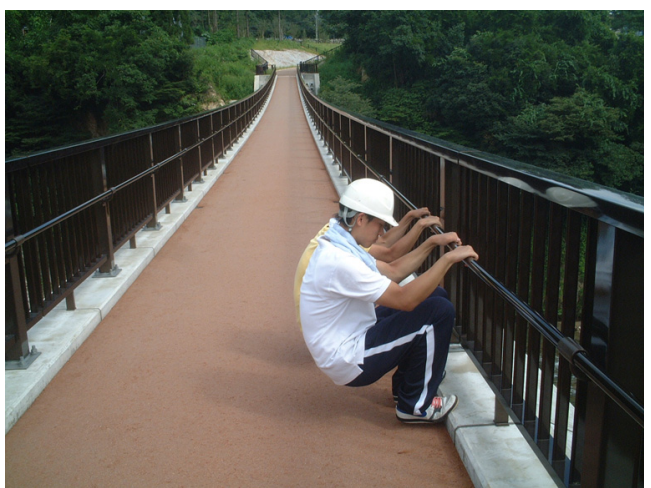

Photo 2. Impact test for lateral vibration mode.

\subsection{Damping-free vibration tests}

The damping-free vibration tests (Photo 3) were conducted by having two people jump continuously in rhythm with a metronome operated at the resonant frequency. After confirming the resonance of the bridge, they stopped the exercise and identified the damping constant of each vibration mode by using the eigensystem realization algorithm (ERA) method [6].

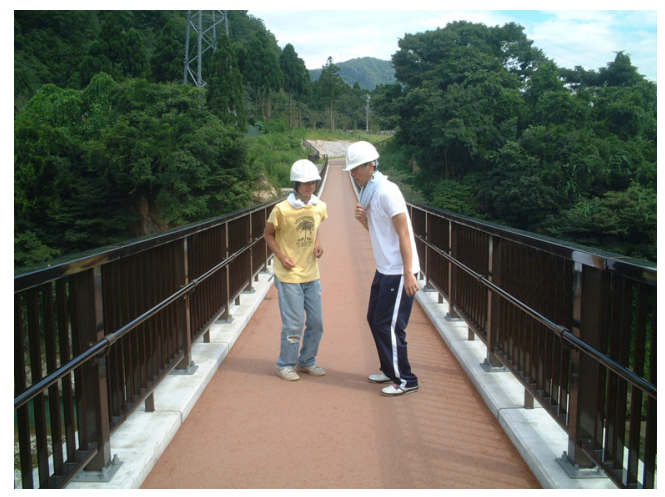

Photo 3. Damping-free vibrations test.

\subsection{First coupled torsional-lateral vibration obtained by examination}

According to the results of the examination, two types of coupled torsional-lateral vibration modes were observed (Fig. 2). These modes, shown in Figs. 2(a) and 2(b), are respectively referred to as the $1^{\text {st }}$ and $2^{\text {nd }}$ coupled torsional-lateral vibration modes.

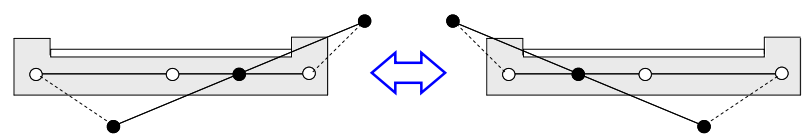

(a) $1^{\text {st }}$ vibration mode

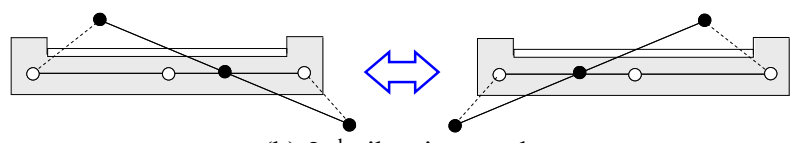

(b) $2^{\text {nd }}$ vibration mode

Figure 2. Coupled torsional-lateral vibration modes.

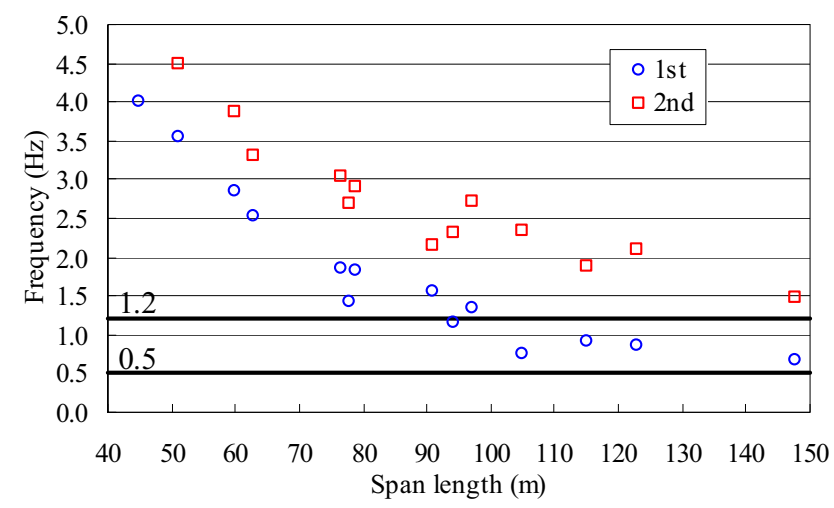

Figure 3. Relation of span lengths to frequency of $1^{\text {st }}$ and $2^{\text {nd }}$ coupled torsional-lateral vibration. 
Figure 3 shows the relation of span length to frequency of $1^{\text {st }}$ or $2^{\text {nd }}$ coupled torsional-lateral vibration in each bridge. These frequency decreases as the span length increases. Although the bridges differ in thickness and deck width, the correlation between span length and frequency is clear. The critical frequency for the lateral vibrations of footbridges subjected to pedestrian walking by the Hivoss guidelines [5] ranges from 0.5 to $1.2 \mathrm{~Hz}$. Some vibration modes appear in this range. The span lengths corresponding to this range are between 80 and $150 \mathrm{~m}$. Therefore, the $1^{\text {st }}$ coupled torsional-lateral vibration mode is studied here at span lengths of 80 to $150 \mathrm{~m}$.

\section{Comparison of analysis and examination}

\subsection{Bridge model}

In this study, the actual PC stress ribbon footbridges were modeled. The stress ribbon deck and lateral member were modeled as a beam element and rigid element, respectively. The force of the suspension tendons that carry the dead load was calculated by using Eq. (1). The axial and shear stiffnesses of the suspension tendons were incorporated into the beam elements of the deck. The boundary condition of the bridge is fixed at the ends of both abutments. An example of an analytical bridge model is shown in Fig. 4:

$$
T=\frac{w L^{2}}{8 s}
$$

where $T, w, L$, and $s$ represent the tension force, dead load per unit length, span length, and sag, respectively.

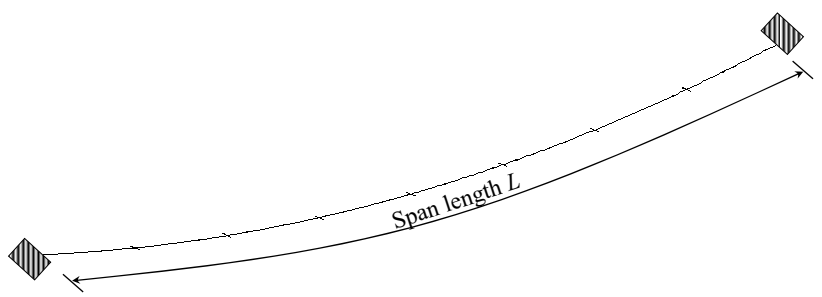

Figure 4. Analytical bridge model

The $1^{\text {st }}$ coupled torsional-lateral vibration (Fig. 5) for the modeled bridges were simulated by eigenvalue analysis.

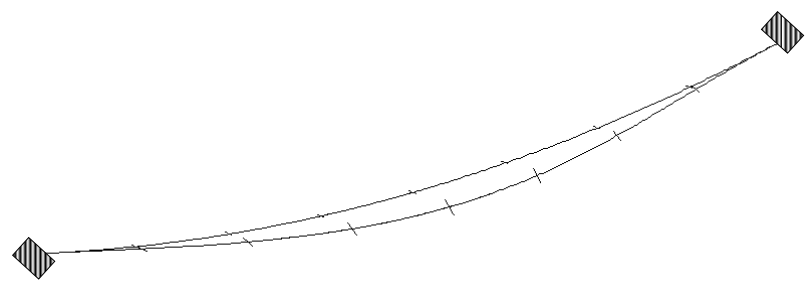

Figure 5. The $1^{\text {st }}$ coupled torsional-lateral vibration mode simulated by the eigen value analysis

\subsection{Frequencies}

Figure 6 shows a comparison of the observed and calculated frequencies for the $1^{\text {st }}$ coupled torsional-lateral vibration. The analytical frequencies were close to the observed results. The bridge model was thus validated. The larger the bridge span, the lower the frequencies of lateral-related vibration modes.

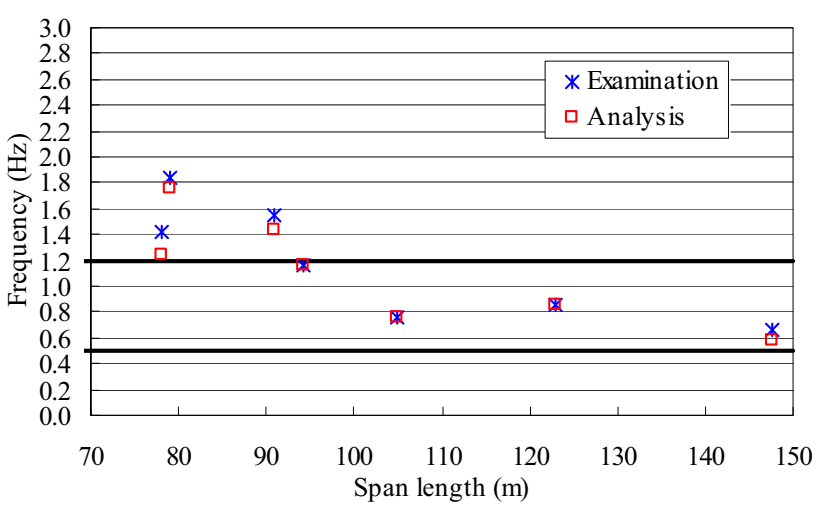

Figure 6. Comparison of the observed and calculated frequencies for the $1^{\text {st }}$ coupled torsional-lateral vibration.

\subsection{Damping}

On the basis of free-vibration wave data obtained by the examinations, the relation between the span length and damping constant of the 1st coupled torsional-lateral vibration by examining actual bridges without widening are shown in Fig. 7 and Table 2. The damping constants obtained by examining each actual bridge ranged from 0.4 to $0.7 \%$. Although the thickness and width of the deck are different, the damping constant of the $1^{\text {st }}$ coupled torsional-lateral vibration shows a decreasing trend as the span length increases.

The damping constant of the $1^{\text {st }}$ coupled torsionallateral vibration was estimated by assuming proportional damping of the strain energy as expressed in Eq. (2).

$$
h_{i}=\sum_{j=1}^{n} D_{j} \cdot \frac{\left\{\phi_{i j}\right\}^{T}\left[K_{j}\right]\left\{\phi_{i j}\right\}}{\left\{\phi_{i}\right\}^{T}[K]\left\{\phi_{i}\right\}}
$$

Here, $h_{i}$ is the damping constant of the $i$ th vibration. $\left\{\phi_{i j}\right\}$ is the mode vector of the material element $j$ in the $i$ th vibration. $D_{j}$ is the material element $j$ of the equivalent damping constant, $\left[K_{j}\right]$ is the stiffness matrix of the material element $j,\left\{\phi_{i}\right\}$ is the global mode vector in the $i$ th vibration, $[K]$ is the stiffness matrix of the global structure, and $n$ is the number of the element.

Although the PC stress ribbon footbridge is composed of tendons and a concrete deck as the material element, most of the strain energy for the $1^{\text {st }}$ coupled torsional-lateral vibration is used by the concrete deck. Hence, only the deck element was used here, and the equivalent damping constant of the deck and damping constant of the $1^{\text {st }}$ coupled torsional-lateral vibration in the PC stress ribbon footbridge was estimated by using Eq. (3). 


$$
h_{1}=D_{d} \cdot \frac{\left\{\phi_{d 1}\right\}^{T}\left[K_{d}\right]\left\{\phi_{d 1}\right\}}{\left\{\phi_{1}\right\}^{T}[K]\left\{\phi_{1}\right\}}
$$

Here, $\left\{\phi_{d 1}\right\}$ is the mode vector of the deck elements in the $1^{\text {st }}$ coupled torsional-lateral vibration, $\left[K_{d}\right]$ is the stiffness matrix of the deck element, and $\left\{\phi_{1}\right\}$ is the global mode vector in the $1^{\text {st }}$ coupled torsional-lateral vibration.

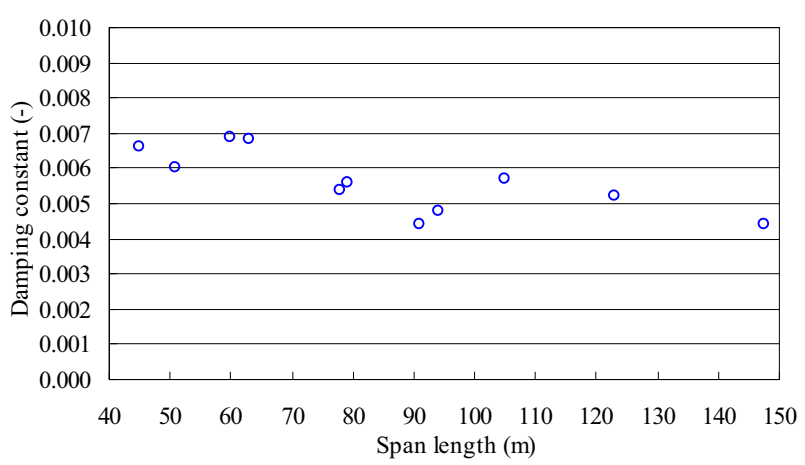

Figure 7. Relation between the span length and the damping constant of the $1^{\text {st }}$ coupled torsional-lateral vibration by examining actual bridges without widening.

Table 2. Damping constants of the $1^{\text {st }}$ coupled torsional-lateral vibration

\begin{tabular}{|r|c|c|c|c|}
\hline $\begin{array}{c}\text { Span } \\
\text { length } \\
(\mathrm{m})\end{array}$ & $\begin{array}{c}\text { ratio of } \\
\text { strain } \\
\text { energy } \\
(-)\end{array}$ & $\begin{array}{c}\text { Damping } \\
\text { constant } \\
\text { (examination) } \\
(-)\end{array}$ & $\begin{array}{c}\text { Damping } \\
\text { constant } \\
\text { estimation) } \\
(-)\end{array}$ & $\begin{array}{c}\text { Equivalent } \\
\text { damping } \\
\text { constant } \\
(-)\end{array}$ \\
\hline 147.6 & 0.72 & 0.0044 & 0.0043 & 0.0061 \\
\hline 123.0 & 0.86 & 0.0052 & 0.0052 & 0.0060 \\
\hline 105.0 & 0.77 & 0.0057 & 0.0046 & 0.0074 \\
\hline 94.0 & 0.87 & 0.0048 & 0.0052 & 0.0055 \\
\hline 91.0 & 0.92 & 0.0044 & 0.0055 & 0.0048 \\
\hline 79.0 & 0.96 & 0.0056 & 0.0058 & 0.0058 \\
\hline 78.0 & 0.88 & 0.0054 & 0.0053 & 0.0061 \\
\hline 63.0 & 0.98 & 0.0068 & 0.0059 & 0.0070 \\
\hline 60.0 & 0.98 & 0.0069 & 0.0059 & 0.0071 \\
\hline 51.0 & 0.98 & 0.0060 & 0.0059 & 0.0061 \\
\hline 45.0 & 0.99 & 0.0066 & 0.0060 & 0.0066 \\
\hline
\end{tabular}

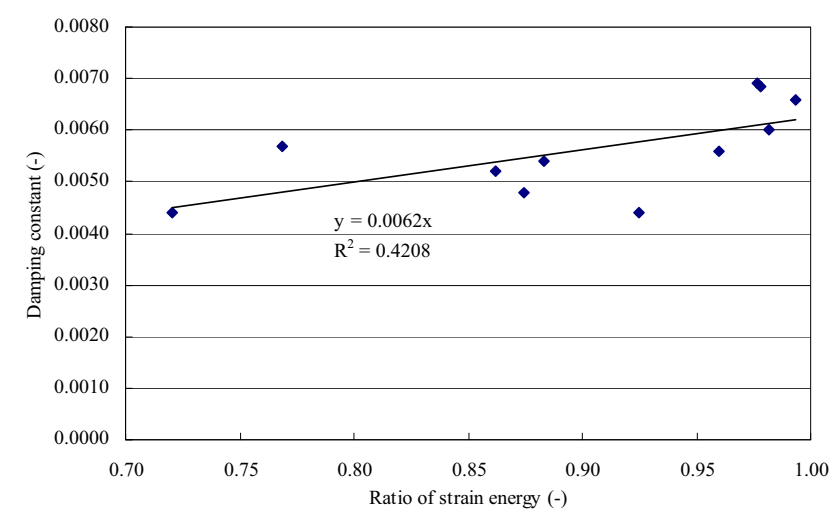

Figure 8. Relation between the ratio of strain energy and the damping constant of the $1^{\text {st }}$ coupled torsional-lateral vibration.

The ratio of the strain energy (the fractional term on the right side of the equation) in each bridge calculated by using Eq. (3) is shown in Fig. 8 and Table 2. According to the relation between the ratio of the strain energy and the damping constant of the $1^{\text {st }}$ coupled torsional-lateral vibration (Fig. 8), the calculated equivalent damping constant of the deck $\left(D_{d}\right)$ was $0.6 \%$ (inclination of Fig. 8). The estimated damping constant (Table 2) of the $1^{\text {st }}$ coupled torsional-lateral vibration, obtained by multiplying the equivalent damping constant of the deck $(0.6 \%)$ by the ratio of the strain energy, was close to the observed result. In this study, considering the issue of safety, $0.6 \%$ was used as the equivalent damping constant of the deck $\left(D_{d}\right)$ for the analytical model.

\subsection{Serviceability}

\subsubsection{Outline of simulation by Hivoss guidelines [6]}

A harmonic load model, which calculates the response of the footbridge due to streams of pedestrians depending on their density, is defined in Eq. (4) for each traffic class (TC; Table 3) according to the Hivoss guidelines.

$$
p(t)=P \cos \left(2 \pi f_{s} t\right) n^{\prime} \psi
$$

Here, $P$ is the component of the force (vertical, $280 \mathrm{~N}$; longitudinal, $140 \mathrm{~N}$; lateral, $35 \mathrm{~N}$ ) due to a single pedestrian with a walking step frequency of $f_{s} ; n^{\prime}$ is the equivalent number of pedestrians on the area of loaded surface $S$; and $\psi$ is the reduction coefficient taking into account the probability that the step frequency approaches the critical range of natural frequencies. Here, the reduction coefficient $\psi$ is defined in Fig. 9, considering the excitation in the first or second harmonic of the pedestrian load. In this guideline, the frequencies of the vertical and longitudinal directions are defined as $1.25 \mathrm{~Hz} \leq f \leq 2.3 \mathrm{~Hz}$. On the other hand, those of the lateral direction are defined as $0.5 \mathrm{~Hz} \leq f \leq 1.2 \mathrm{~Hz}$.

Table 3. Pedestrian traffic classes and densities [5]

\begin{tabular}{|c|c|c|}
\hline $\begin{array}{c}\text { Traffic } \\
\text { class }\end{array}$ & $\begin{array}{c}\text { Density } \\
\left(\text { Pedestrian } / \mathrm{m}^{2}\right)\end{array}$ & Description \\
\hline TC1 & 15 Pedestrian/S & Very weak \\
\hline TC2 & 0.2 & Weak \\
\hline TC3 & 0.5 & Dense \\
\hline TC4 & 1.0 & Very dense \\
\hline TC5 & 1.5 & Exceptionally dense \\
\hline
\end{tabular}

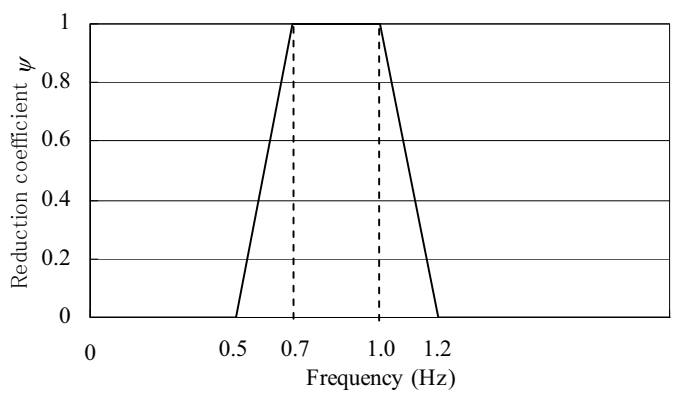

Figure 9. Reduction coefficient (lateral direction) [5]. 
The equivalent number of pedestrians $n^{\prime}$ is defined [5] as in Eq. (5) or Eq. (6) for TC1-TC3 (density $d<1.0$ Pedestrians $/ \mathrm{m}^{2}$ ) or TC4-TC5 (density $d \geq 1.0$ Pedestrians $/ \mathrm{m}^{2}$ ), respectively. A harmonic load is applied as shown in Fig. 10.

$$
\begin{gathered}
n^{\prime}=\frac{10.8 \sqrt{\xi \cdot n}}{S} \\
n^{\prime}=\frac{1.85 \sqrt{n}}{S}
\end{gathered}
$$

Here, $\xi$ is the structural damping constant and $n$ is the number of the pedestrians on the loaded surface $S$ ( $n=S$ $\times d)$.

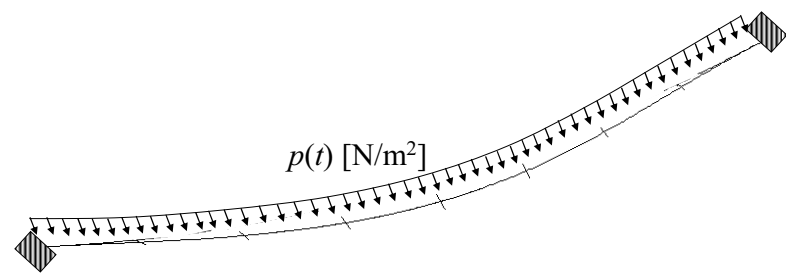

Figure 10. Application of a harmonic load

The maximum acceleration obtained by dynamic response analysis at the resonance frequency can be calculated by Eq. (7), using the equivalent single degree of freedom system. In this method, a single degree of freedom system, which is equal to the natural frequency and the damping of the bridge, is assumed.

$$
a_{i, j, \max }=\frac{P_{i}^{*}}{M_{i}^{*}} \frac{1}{2 \xi_{i}} \phi_{i, j}
$$

where $P_{i}^{*}, M_{i}^{*}, \xi_{i}$, and $\phi_{i, j}$ are the generalized load, modal mass, damping constant, and modal vector, respectively, at the measurement point $j$ in the $i$ th vibration.

Table 4 shows the criteria [5] for four comfort classes represented as limiting the acceleration of the footbridge. Moreover, this guideline defines the trigger acceleration amplitude to be 0.1 to $0.15 \mathrm{~m} / \mathrm{s}^{2}$ when the lock-in phenomenon begins. Therefore, estimation of the vibration serviceability requires that the comfort level and criteria for lateral lock-in be verified.

Table 4. Comfort classes with common acceleration ranges [5]

\begin{tabular}{|c|c|c|c|}
\hline $\begin{array}{c}\text { Comfort } \\
\text { class }\end{array}$ & Degree of comfort & Limit (Vertical) & Limit (Lateral) \\
\hline CL1 & Maximum & $<0.50 \mathrm{~m} / \mathrm{s}^{2}$ & $<0.10 \mathrm{~m} / \mathrm{s}^{2}$ \\
\hline CL2 & Medium & $0.50-1.00 \mathrm{~m} / \mathrm{s}^{2}$ & $0.10-0.30 \mathrm{~m} / \mathrm{s}^{2}$ \\
\hline CL3 & Minimum & $1.00-2.50 \mathrm{~m} / \mathrm{s}^{2}$ & $0.30-0.80 \mathrm{~m} / \mathrm{s}^{2}$ \\
\hline CL4 & Unacceptable discomfort & $>2.50 \mathrm{~m} / \mathrm{s}^{2}$ & $>0.80 \mathrm{~m} / \mathrm{s}^{2}$ \\
\hline
\end{tabular}

\subsubsection{Results of simulation}

The maximum accelerations for the $1^{\text {st }}$ coupled torsionallateral vibration in each bridge at the span center (lateral direction) were simulated using Eq. (7). Figure 11 shows the maximum accelerations at each pedestrian density (TC1-TC5; Table 3) in each bridge, which have frequencies of $0.5-1.2 \mathrm{~Hz}$. The comfort class (CL1-CL4; Table 4) of the guidelines also show in this figure.

This guideline defines the trigger acceleration amplitude to be 0.1 to $0.15 \mathrm{~m} / \mathrm{s}^{2}$ when the lock-in phenomenon begins [5]. These cases are almost within CL2 whereas that one bridge which has the $0.76 \mathrm{~Hz}$ frequency appeared larger acceleration amplitude at TC4 and TC5. This may due to its light self-weight in light of its small width.

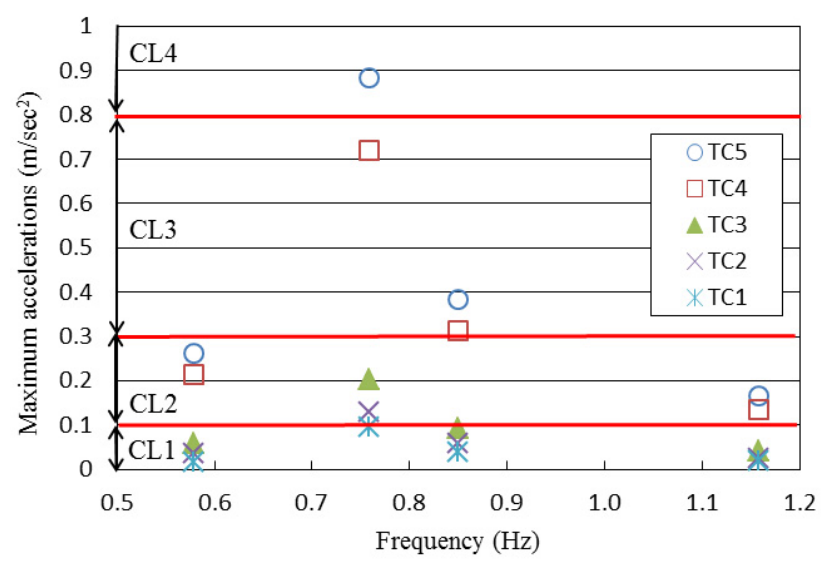

Figure 11. Maximum accelerations at a high pedestrian density TC5 in each bridge.

\section{Conclusions}

The vibration tests in this study were performed for 14 single span prestressed concrete stress ribbon footbridge with various span lengths under human-induced excitation to assess the vibration characteristics of the bridges. On the basis of the experimental results, the performances of the lateral vibration serviceability for these bridges were estimated by using Hivoss guidelines.

The following knowledge was obtained in this study.

(1) The frequencies of the $1^{\text {st }}$ and $2^{\text {nd }}$ coupled torsionallateral vibrations for actual bridges decreased as the span length increased. Although these bridges differed in thickness and width of deck, the frequencies correlated with the span length. The span lengths for the range of lateral vibrations (0.5-1.2 $\mathrm{Hz}$ ) recommended by the guidelines ranged from 80 to $150 \mathrm{~m}$.

(2) The $1^{\text {st }}$ coupled torsional-lateral vibration for actual bridges were simulated by eigenvalue analysis. A comparison of the observed and estimated frequencies of the $1^{\text {st }}$ coupled torsional-lateral vibration revealed that the analytical frequencies were close to the test results. The bridge model was thus validated. 
(3) The free-vibration tests for actual bridges revealed that the damping constants of the $1^{\text {st }}$ coupled torsional-lateral vibration ranged from 0.4 to $0.7 \%$.

(4) From the relation between the ratio of the strain energy and the damping constant of the $1^{\text {st }}$ coupled torsional-lateral vibration, the calculated equivalent damping constant of the deck $\left(D_{d}\right)$ was $0.6 \%$. The damping constant of the $1^{\text {st }}$ coupled torsional-lateral vibration estimated by multiplying the equivalent damping constant of the deck $(0.6 \%)$ by the ratio of the strain energy was close to the observed result.

(5) By the estimation of the lateral vibration serviceability for actural bridges using Hivoss guidelines, it is clear that one bridge which has the frequency of $0.76 \mathrm{~Hz}$ has large acceleration amplitude at TC4 and TC5. This may due to its light self-weight in light of its small width.

\section{References}

1. Strasky, J., Stress ribbon and cable-supported pedestrian bridges, Tomas Telford (2005).

2. Fujino, Y., Pacheco, B. M., Nakamura, S., and Warnitcahi, P., Synchronization of human walking observed during lateral vibration of a congested pedestrian bridge, Earthquake Eng. Struct. Dyn., 22(9), 741-758, (1993).

3. Dallard, P., Fitzpatrick, T., Flint, A., Low, A., Smith, R. R., Willford, M., and Roche, M., London Millennium Bridge: Pedestrian-induced lateral vibration, J. Bridge Eng., 6(6), 412-417, (2001).

4. Nakamura, S., Field measurements of lateral vibration on a pedestrian suspension bridge, Struct. Eng., 81(22), 22-26, (2003).

5. Human induced vibration of steel structures guidelines, (2007).

(http://www.stb.rwthaachen.de/projekte/2007/HIVOSS/download.php)

6. Juang, J. N. and Pappa, R. S., An eigensystem realization algorithm for modal parameter identification and model reduction, J. Guid.Control Dynam., 8(5), 620-627, (1985). 